\title{
MORFOLOGIA, GERMINAÇÃO E TEOR DE ÁGUA DAS SEMENTES DE ARAÇÁ-BOI (Eugenia stipitata ssp. sororia)
}

\author{
Antônio Mauro G. dos ANJOS', Isolde D. Kossmann FERRAZ ${ }^{2}$
}

RESUMO - O araçá-boi (Eugenia stipitata ssp. sororia McVaugh - Myrtaceae) é uma espécic frutifera originária da Amazônia Ocidental que apresenta grande potencial para a indústria de sucos e sorvetes. A morfologia das sementes é complexa e sua fisiologia pouco compreendida. Sabe-se que elas são resistentes a injürias mecânicas e sensiveis ao dessecamento. Objetivou-se caracterizar a morfologia das sementes através da biometria, determinar o grau de umidade das sementes $\mathrm{e}$ descrever os eventos do processo germinativo, visando dar subsidios para o manejo das sementes e a produção de mudas. As médias de comprimento, peso fresco e peso seco das sementes foram de $1,06 \mathrm{~cm}, 0,49 \mathrm{~g} \mathrm{e} 0,17 \mathrm{~g}$, respectivamente. O teor de água encontrado nas sementes foi de $62 \%$. A germinação das sementes é hipógea e criptocotiledonar, mostrando-se lenta e desuniforme. A germinação iniciou-se por volta de 50 dias e estendeu-se até mais de 280 dias. A plântula, com 60 dias, apresentou altura média de $13 \mathrm{~cm}$ e 18 folhas. As sementes apresentam alto poder de regeneração pois, mesmo quando cortadas ao meio ou na zona meristemática, foram capazes de formar plântulas.

Palavras chave: Eugenia Stipitata, Germinação de Sementes, Morfologia de Sementes, Sementes Recalcitrantes, Sementes Pseudomonocotiledonares, Frutifera da Amazônia.

Morphology, Germination and Water Content of Seeds of Araçá-boi (Eugenia stipitata ssp. sororia)

ABSTRACT - Araçá-boi (Eugenia stipitata ssp. sororia McVaugh - Myrtaceac) is a fruit tree native to western Amazonia. It has considerable potential in the juice and ice-cream industries. Seeds of araça-boi have a complex morphology and their physiology is not well understood. They are known to be resistent to mechanical injury and sensitive to drying. This study undertakes a biometric characterization of seed morphology, determines seed water content and describes the germination process, with a view to aiding seed handling and seedling production. Average seed length, fresh and dry weight were found to be 1.06 $\mathrm{cm}, 0.49 \mathrm{~g}$ and $0.17 \mathrm{~g}$ respectively. The water content was $62 \%$. Germination, which is hypogeal and cryptocotyledonous, was observed to be slow and far from uniform; the first seeds germinated after about 50 days, while others took longer than 280 days. Sixty-day-old seedlings had an average height of $13 \mathrm{~cm}$ and had 18 leaves. Seeds showed a high capacity for regeneration; even when cut in the middle or in the meristematic zone, they still formed seedlings.

Key words: Eugenia stipitata, seed germination, seed morphology, recalcitrant seeds, pseudomonocotyledonous seeds, Amazonian fruit tree.

\section{INTRODUÇÃO}

O araçá-boi (Eugenia stipitata ssp. sororia McVaugh - Myrtaceae) é uma espécie frutífera originária da Amazônia Ocidental, que apresenta grande potencialidade econômica, principalmente para a produção de sucos, sorvetes, cremes e compotas (Clement, 1983; Chavez
Flores \& Clement, 1984). As sementes são exalbuminosas (Flores \& Rivera, 1989) e recalcitrantes (Chavez Flores \& Clement, 1984; Gentil \& Ferreira, 1999).

A morfologia do embrião é utilizada taxonomicamente para caracterizar as tribos de Myrtaceae e especialmente o gênero Eugenia (McVaugh, 1956, 1958). O embrião da

1 Programa de Pós-Graduação em Biologia Tropical e Recursos Naturais (PPG-BTRN). Mestrado em Botânica. INPA - Coordenação de Pós-Graduação, Cx. Postal 478, CEP 69.011-970, Manaus-AM, Brasil. 2 Instituto Nacional de Pesquisas da Amazônia-INPA, Coordenação de Pesquisas em Silvicultura Tropical, Cx. Postal 478, CEP 69.011-970, Manaus-AM, Brasil. 
espécie é pseudomonocotiledonar, ou seja, os cotilédones são parcialmente concrescidos entre si (McVaugh, 1956, 1958; Flores \& Rivera, 1989). A morfologia das sementes pseudomonocotiledonares ainda é pouco compreendida, mas sabe-se que em araçá-boi, o tamanho e o peso das sementes são diretamente proporcionais à qualidade das mudas produzidas (Ferreira, 1989).

Observações preliminares atestaram que as sementes de araçá-boi são resistentes a injúrias mecânicas (por exemplo cortes). A morfologia da germinação de sementes cortadas ao meio e no local de emergência da radicula (zona meristemática) foi comparada com a germinação em sementes intactas.

Este trabalho objetivou caracterizar a morfologia das sementes através da biometria; determinar o grau de umidade das sementes e descrever os eventos do processo germinativo, comparando-o com a germinação nas sementes submetidas a cortes.

\section{MATERIAL E MÉTODOS}

Os frutos maduros foram coletados na região de Manaus e após a remoção manual da polpa, as sementes foram friccionadas com serragem, areia e água (1:2:1), para a remoção das fibras, e então, lavadas com água em abundância.

Para os estudos morfológicos tomou-se, ao acaso, 100 sementes oriundas de um plantio localizado à rod. BR 174, km 14, em Manaus, coletadas em março/96. Determinou-se o comprimento, largura, espessura e peso fresco das sementes. Através da observação da morfologia, determinaram- se regiões da semente, estabelecendo-se nomenclatura específica. Para observar o sistema radicular e garantir o seu completo desenvolvimento, as sementes foram semeadas individualmente em tubetes de $20 \mathrm{~cm}$ de altura por $5 \mathrm{~cm}$ de diâmetro, contendo serragem curtida, como substrato.

Realizou-se teste de germinação no viveiro do INPA/CPCA, em Manaus. Utilizaram-se caixas retangulares de plástico branco $(56 \times 37 \times 10 \mathrm{~cm})$, com substrato de areia lavada (cerca de $4 \mathrm{~cm}$ ). As sementes foram semeadas sobre o substrato e cobertas com uma camada de $2 \mathrm{~cm}$ de vermiculita média expandida (diâmetro médio do grão: $1,4 \mathrm{~mm}$ ) e o critério de germinação foi a emergência do epicótilo na superficie. Utilizou-se quatro repetições de 25 sementes intactas $(n=100)$. Deste mesmo ensaio foram tomadas plântulas com 60 dias após a emergência do epicótilo, para os estudos morfológicos. A biometria das plântulas baseou-se em 25 individuos, escolhidos pelo bom estado fitossanitário, dentro dos seguintes parâmetros: altura da parte aérea, diâmetro do colo, número total de folhas (exceto catáfilos com menos de $2 \mathrm{~mm}$ ) e média de comprimento do par de folhas proximal, mediano e distal.

As sementes destinadas à injúria por corte foram semeadas nas mesmas condições e local que as sementes do teste de germinação, sendo: a) tomouse 100 sementes intactas que foram cortadas transversalmente ao meio com lâmina de barbear, e após o corte, as duas metades foram semeadas ladoa-lado, com as superficies dos cortes voltadas para baixo; b) tomou-se 100 sementes intactas e, utilizando-se 
lâmina de barbear, realizou-se cortes de $1 \mathrm{~mm}$, removendo-se apenas a zona meristemática.

Comparou-se o teor de água de sementes individuais recém-beneficiadas, oriundas de três coletas na região de Manaus:

a) 20 sementes (coleta de 20 a 24/11/95 no INPA/CPCA)

b) 100 sementes (coleta de 24 a 31/03/96 na BR $174 \mathrm{~km} \mathrm{14)}$

c) 225 sementes (coleta de 24 a 28/06/96 na Universidade do Amazonas-FCA)

Após a extração, todas as sementes foram torcidas em um pano seco para retirar o excesso de água do tegumento. Nas amostras $a$ e $c$ selecionou-se apenas as sementes de tamanho médio, excluindo as muito pequenas $(<8 \mathrm{~mm})$, enquanto que em $b$ manteve-se sementes de todas as dimensões. As sementes foram secas em estufa sem ventilação forçada, à temperatura de $75^{\circ} \mathrm{C}\left( \pm 1^{\circ} \mathrm{C}\right)$, até peso constante. $\mathrm{O}$ teor de água foi calculado com base no peso fresco individual.

\section{RESULTADOS E DISCUSSÃO}

\section{Características morfológicas da semente}

A semente apresenta tegumento delgado, coriáceo, maleável, permeável e absorvente. A superfície externa é marrom-escuro, com aspecto de couro-camurça (Fig. 01). Internamente, o tegumento é liso e marrom-claro. Apresenta grande variabilidade quanto à forma, podendo apresentar-se reniforme, achatada, discoidal, com comprimento superior à largura ou vice-versa, ou até quase esférica. Contudo, predomina a morfologia reniforme, com um achatamento lateral (Fig. 1), permitindo a realização de medidas de espessura, comprimento e largura.

A semente madura é exalbuminosa, isto é, sem endosperma, monoembriônica e o embrião não apresenta eixo embrionário distinto. A monoembrionia também foi confirmada em Eugenia brasiliensis, E. uniflora, E. tomentosa, E. uvalha, E. lucescens e $E$. myrcianthes, ao passo que muitas espécies de gêneros relativamente próximos, como Syzygium e Myrciaria, apresentam poliembrionia muito evidente (Lughadha \& Proença, 1996).

Numa das extremidades há uma discreta proeminência que, na semente sem tegumento, é mais conspicua e convencionou-se chamá-la, neste trabalho, de "zona meristemática" (Figs. 1C, 1D, 1E). Trata-se da região que contém uma estrutura unciforme, menor que $1 \mathrm{~mm}$, às vezes quase imperceptivel. É deste local que emerge a radícula e o epicótilo.

Toledo \& Marcos Filho (1977) consideram imatura a semente cujo embrião não está anatomicamente estruturado na ocasião da maturação do fruto, ou seja, quando não apresenta radícula, hipo e epicótilo. A semente de araçá-boi se enquadra nesta categoria de imaturidade, pois não apresenta eixo embrionário típico.

$\mathrm{O}$ embriâo é composto apenas pela massa cotiledonar volumosa e branco-leitosa que é, possivelmente, o resultado da fusão lateral e parcial dos cotilédones, constituindo "áreas de 
A

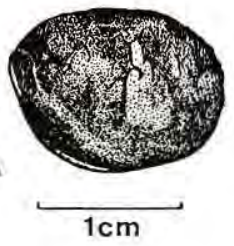

B
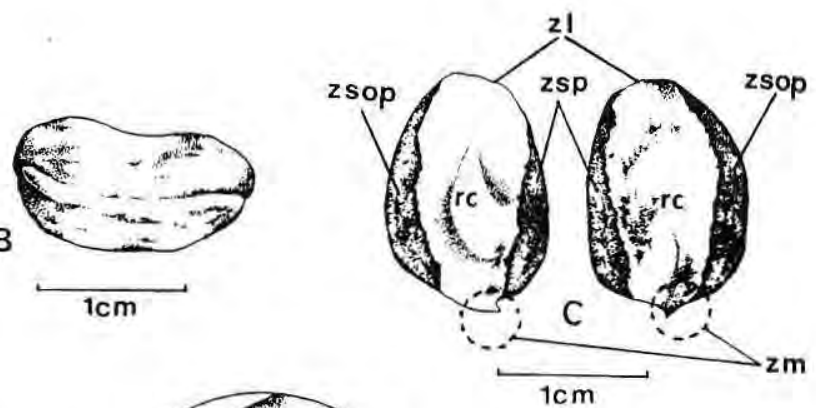
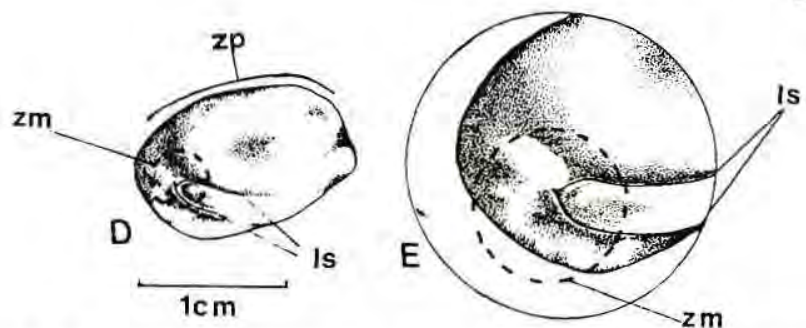

Figura 1. Morfologia da semente de araçá-boi (Eugenia stipitata ssp. sororia McVaugh). A) Semente intacta, com tegumento. B) Semente destegumentada, em vista lateral. C) Vista interna da semente com os cotilédones separados após cozimento, evidenciando: $\mathbf{z l}$ - zona livre (sem soldadura); zsp - zona de soldadura dos cotilédones no lado da placentação (neste local não se observa, externamente, as linhas de soldadura); zm - zona meristemática; zsop - zona de soldadura dos cotilédones no lado oposto ao da placentação (neste local observa-se, externamente, um par de linhas de soldadura longitudinais que convergem para a zona meristemática); rc - região central das superficies adaxiais dos cotilédones. D) Vista frontal da semente destegumentada, evidenciando: $\mathbf{~} \mathbf{m}$ - zona meristemática; Is - linhas de soldadura; zp - zona de placentação. E) Vista frontal da semente destegumentada ampliada, evidenciando: $\mathbf{z m}$ zona meristemática; Is - linhas de soldadura.

soldadura" lateral (Fig. 1). Esta fusão parcial dos cotilédones caracteriza um embrião conhecido na literatura como pseudomonocotiledonar (McVaugh 1956, 1958; Font Quer, 1985; Flores \& Rivera, 1989). Observa-se que uma das áreas de fusão apresenta, externamente, "linhas de soldadura" dos cotilédones (Figs. 1D, IE), visíveis apenas após a retirada do tegumento e que convergem para a zona meristemática. As linhas de soldadura dispõem-se longitudinalmente, na lateral oposta à zona de ligação da semente ao fruto ou "zona de placentação" (Fig. ID). A soldadura dos cotilédones impede que eles sejam separados sem serem danificados. $\mathrm{Na}$ extremidade oposta à zona meristemática há uma "zona livre" ou sem soldadura (Fig. 1C) onde, contudo, os cotilédones mantêm-se firmemente aderidos, tal como na região central de suas superfícies adaxiais (Fig. 1C).

A semente não apresenta odores e os cotilédones não são gordurosos ao tato, contudo, quando feridos, tornam-se marrom-avermelhados no local do ferimento, provavelmente devido à oxidação dos compostos fenólicos presentes.

As sementes apresentam, entre si, intensa variabilidade biométrica, com comprimento máximo de $1,93 \mathrm{~cm}$ e mínimo de $0,60 \mathrm{~cm}$ e peso fresco máximo de $1,62 \mathrm{~g}$ e minimo de $0,13 \mathrm{~g}$ (Tab. 1). Ferreira (1989) separou 
Tabela 1. Biometria das sementes de araçá-boi (Eugenia stipitata ssp. sororia McVaugh) coletadas em $31 / 03 / 1996$ em plantio particular localizado no $\mathrm{km} 14$ da rodovia BR 174, em Manaus $(n=100)$.

\begin{tabular}{lccccc}
\hline & $\begin{array}{c}\text { Comprim. } \\
(\mathrm{cm})\end{array}$ & $\begin{array}{c}\text { Largura } \\
(\mathrm{cm})\end{array}$ & $\begin{array}{c}\text { Espessura } \\
(\mathrm{cm})\end{array}$ & $\begin{array}{c}\text { Peso } \\
\text { fresco }(\mathrm{g})\end{array}$ & $\begin{array}{c}\text { Peso } \\
\text { seco }(\mathrm{g})\end{array}$ \\
\hline Média & 1,06 & 0,88 & 0,62 & 0,49 & 0,17 \\
D. P.* & 0,265 & 0,176 & 0,116 & 0,302 & 0,120 \\
Máximo & 1,93 & 1,36 & 0,89 & 1,62 & 0,61 \\
Mínimo & 0,60 & 0,61 & 0,25 & 0,13 & 0,03 \\
\hline
\end{tabular}

* Desvio Padrão

sementes de araçá-boi de um mesmo lote em quatro classes de tamanho e peso, obtendo médias de comprimento máximo de $2,75 \mathrm{~cm}$ e mínimo de 1,55 $\mathrm{cm}$ e peso fresco máximo de $4,05 \mathrm{~g}$ e minimo de $1,03 \mathrm{~g}$. As médias, notavelmente maiores que as encontradas neste trabalho, devem-se, provavelmente, às diferenças de local e data de colheita. É possível que sementes de colheitas de um mesmo plantio apresentem dados biométricos muito distintos, quando coletadas ao longo de um ano. O tamanho das sementes tem consequência para o vigor das mudas produzidas e acredita-se que, através da eliminação das sementes pequenas, pode-se melhorar a qualidade das mudas produzidas (Ferreira, 1989).

\section{Teor de água das sementes}

Foi determinado o teor de água de sementes das três procedências (Tab. 2). Sementes recém-extraidas dos frutos, provenientes dos plantios do INPA (V8), da BR $174 \mathrm{~km} 14$ e da Universidade do Amazonas, apresentaram entre 59 e 66 $\%$ de água. A pequena diferença de teor de água entre as coletas (cerca de $7 \%$ ) pode estar relacionada com o sítio de coleta (umidade e nutrientes do solo) ou a época do ano (principalmente pluviosidade). Entretanto, a diferença entre os valores mínimos e máximos, dentro de cada lote $(20-26 \%)$, pode estar relacionada com a variabilidade genética e com o tamanho das sementes. A grande variação de tamanho é comum em sementes de

Tabela 2. Teor de água de sementes frescas de araçá-boi (Eugenia stipitata ssp. sororia McVaugh) coletadas em diferentes locais.

\begin{tabular}{lcccccc}
\hline \multirow{2}{*}{ PROCEDÊNCIA } & DATA & Ne & \multicolumn{3}{c}{ TEOR } & DE ÁGUA (\%) \\
& COLETA & SEMENTES & Média & D. P.* & Máx & Mín. \\
\hline INPA/CPCA(V8) & $24 / 11 / 95$ & 20 & 59,03 & 5,450 & 68,65 & 48,43 \\
BR 174 km 14 & $31 / 03 / 96$ & 100 & 65,92 & 5,339 & 78,71 & 52,37 \\
Universidade(FCA) & $28 / 06 / 96$ & 225 & 62,00 & 4,487 & 73,10 & 50,88
\end{tabular}

* Desvio Padrão 
espécies tropicais. $\mathrm{O}$ fato de selecionar as sementes e homogeneizá-las por tamanho (sementes do INPA e da Universidade) também pode ter afetado o resultado do teor de água, pois as sementes não selecionadas da BR 174, apresentaram maior amplitude (26\%). King \& Roberts (1979) citam graus de umidade de sementes de cerca de 150 espécies e, nesta lista, poucas sementes apresentam teor de água acima de $60 \%$. Por isso, os valores obtidos para a espécie estudada podem ser considerados altos.

\section{Morfologia da germinação e da plântula}

A germinação das sementes de araçá-boi é hipógea e criptocotiledonar, segundo a tipologia proposta por Hladik \& Miquel (1990).

Os eventos da germinação podem ser vistos na Figura 2. A germinação inicia-se com uma expansão na zona meristemática, formando uma pequena protuberância. Em seguida, dá-se o desenvolvimento geotrópico positivo da radícula, rompendo o tegumento. $\mathrm{Na}$ maioria dos indivíduos observados, o epicótilo surge muito depois da radícula, no mesmo local da protuberância, em sentido geotrópico negativo. O epicótilo desenvolve-se sempre retilíneo e, quando emerge na superfície, apresenta dois a cinco catáfilos.

Durante todo o processo germinativo, não se observou entumescimento da semente. Na plântula de 60 dias (Fig. 3), pode-se observar a morfologia foliar típica da espécie e a estrutura, ainda intacta, da massa cotiledonar.

Flores \& Rivera (1989), estudando a germinação das sementes de araçá-boi, assinalaram que "após a saida da radicula inicia-se o desenvolvimento de estruturas peciolares em um nó cotiledonar, que se projetam até o exterior e formam um arco, através do qual emerge o epicótilo". Esta afirmação contradiz o que foi observado no presente trabalho. Os peciolos cotiledonares não são distinguiveis e não se observa um arco distinto, mas no seu local desenvolve-se uma estrutura semelhante a um callus.

A emergência do epicótilo na superfície é lenta e desuniforme, levando mais de 50 dias para se iniciar e cerca de 280 dias para terminar (Fig. 4). Estes dados concordam com os de Pinedo Panduro et al. (1981) e confirmam a dormência das sementes de araçá-boi. Esta dormência parece ser principalmente tegumentar (Pinedo Panduro et al., 1981; Gentil \& Ferreira, 1999), mas pode ser causada também pela ausência de um eixo embrionário e pela possível presença de substâncias químicas inibidoras da germinação.

Observou-se que, na presença da luz, os catáfilos são verdes, tanto nos experimentos de viveiro quanto nos de laboratório, indicando atividade fotossintética. Os primeiros pares de folhas são diminutos, entre 0,2 e 1,1 cm (Tab. 3), e apresentam filotaxia oposta decussada (Figs. 2g, 3). Cada par de folhas que surge nesta fase tem seu crescimento final sempre maior que o do par anterior. As médias de comprimento dos pares de folhas proximais, medianos e distais de 25 plântulas foram $0,44 \mathrm{~cm}, 1,82 \mathrm{~cm}$ e $3,37 \mathrm{~cm}$, respectivamente. Isto confere à plântula um padrão de arquitetura 

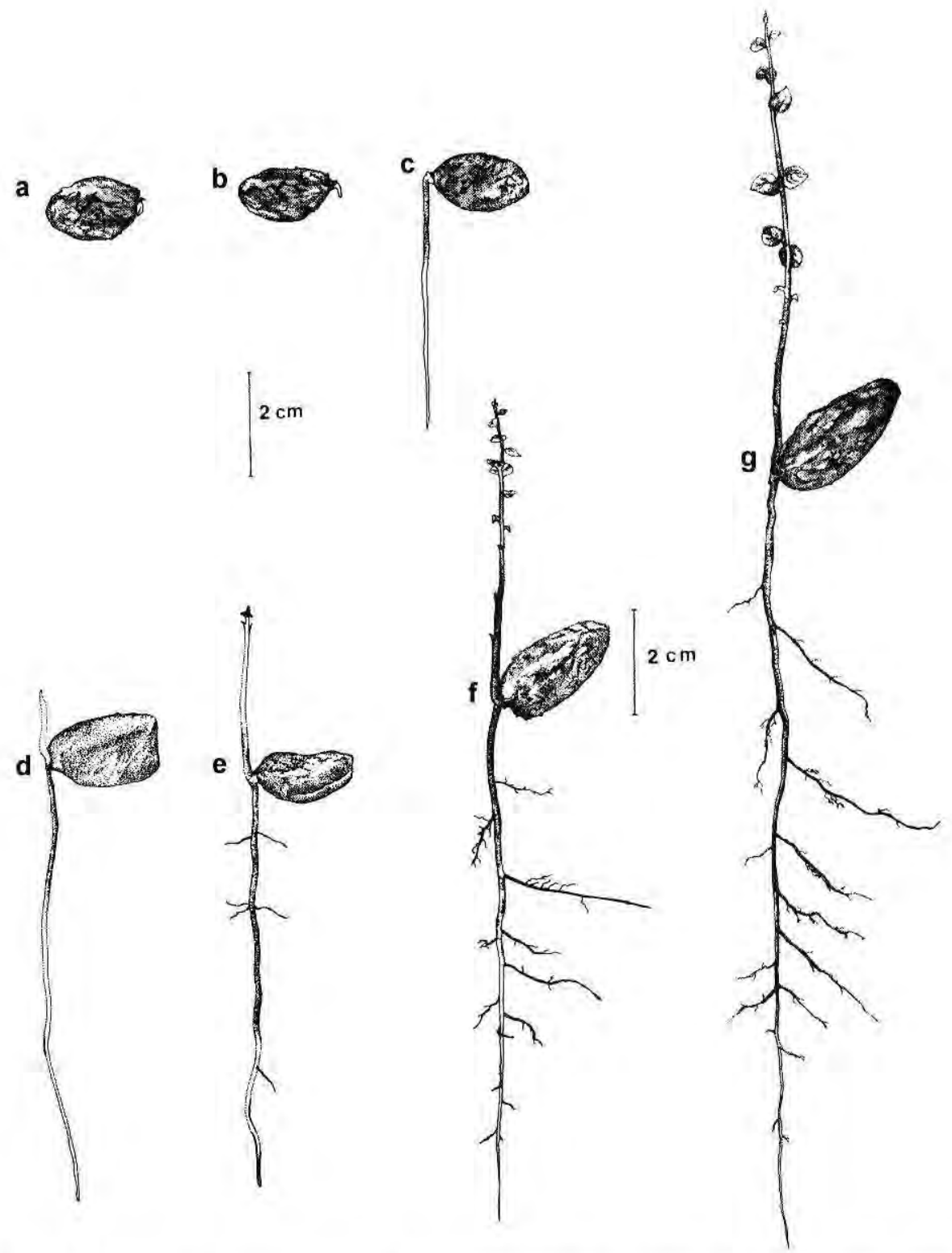

Figura 2. Germinação da semente de araçá-boi (Eugenia stipitata ssp. sororia McVaugh): a) crescimento da zona meristemática; b) protusão geotrópica da radicula; $c$ ) crescimento da raiz primária; d) emergência do epicótilo; e) crescimento do epicótilo e da raiz; f-g) formação da plântula. 


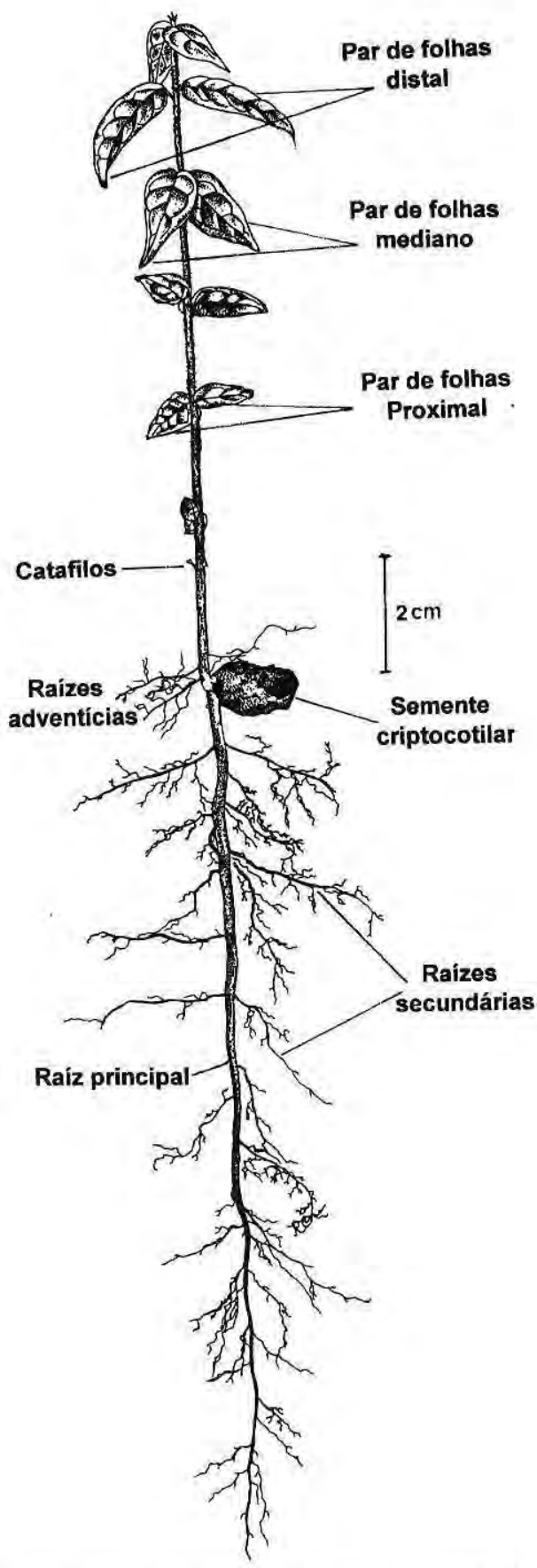

Figura 3. Plântula de araçá-boi (Eugenia stipitata ssp. sororia McVaugh) com cerca de 60 dias após a emergência do epicótilo, evidenciando a germinação criptocotiledonar. 


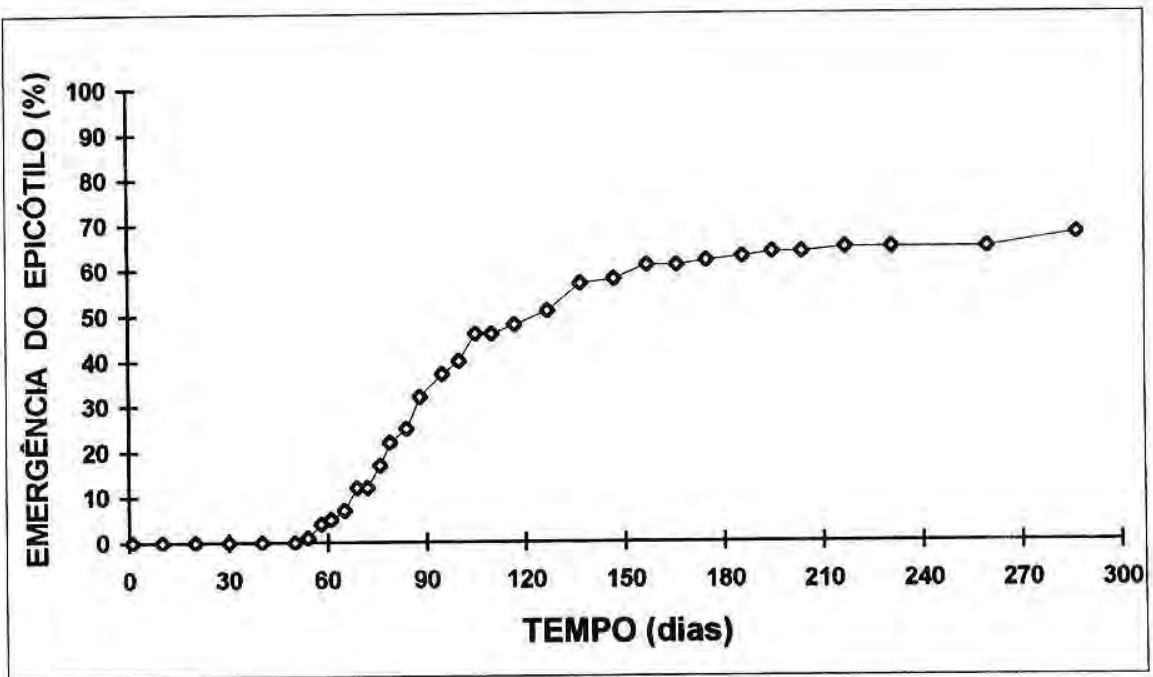

Figura 4. Curva de germinação das sementes intactas de araçá-boi (Eugenia stipitata ssp. sororia McVaugh), semeadas no viveiro do INPA/CPCA, em Manaus $(n=100)$.

Tabela 3. Biometria de plântulas de araçá-boi (Eugenia stipitata ssp. sororia McVaugh), 60 dias após a emergência do epicótilo (sementes maiores que $0,8 \mathrm{~mm}$, coletadas em 16/07/1996 no plantio da FCA UFAM e semeadas no viveiro do INPA/CPCA, em Manaus $(n=25)$.

\begin{tabular}{lcccccc}
\hline & $\begin{array}{c}\text { Altura } \\
\text { parte } \\
\text { aérea } \\
(\mathrm{cm})\end{array}$ & $\begin{array}{c}\text { Diâmetro } \\
\text { do colo } \\
(\mathrm{cm})\end{array}$ & $\begin{array}{c}\text { Quantidade } \\
\text { de folhas }\end{array}$ & & \multicolumn{3}{c}{ Comprimento foliar } \\
\cline { 6 - 8 } & & & & $\begin{array}{c}\text { Primeiro par } \\
\text { proximal } \\
(\mathrm{cm})\end{array}$ & $\begin{array}{c}\text { Par } \\
\text { mediano } \\
(\mathrm{cm})\end{array}$ & $\begin{array}{c}\text { Último par } \\
\text { maduro } \\
\text { distal } \\
(\mathrm{cm})\end{array}$ \\
\hline Média & 12,89 & 0,12 & 17,64 & 0,44 & 1,82 & 3,37 \\
D.P.* & 1,243 & 0,013 & 2,914 & 0,209 & 0,297 & 0,479 \\
Máx. & 15,99 & 0,15 & 22,00 & 1,16 & 2,36 & 4,30 \\
Mín. & 10,26 & 0,09 & 12,00 & 0,22 & 1,23 & 2,54 \\
\hline
\end{tabular}

\section{* Desvio Padrão}

caliciforme (Fig. 3). Plântulas de 60 dias apresentaram, em média, $13 \mathrm{~cm}$ de altura e 18 folhas (Tab. 3).

Segundo Hladik \& Miquel (1990), em sementes com hipocótilo reduzido ou ausente, a germinação é hipogeal. As sementes de araçá-boi, portanto, se enquadram nesta categoria. Outros autores observaram que o epicótilo é vestigial e não se desenvolve (Flores \& Rivera, 1989), e que a radícula é muito curta no embrião das espécies da subtribo Eugeniinae (McVaugh, 1956). Diferentemente, no presente trabalho constatou-se que o epicótilo é inexistente na semente madura e a estrutura unciforme, semelhante a uma radícula, não parece ser como tal, mas sim uma zona meristemática indiferenciada. Ambos, radícula e epicótilo, se desenvolvem a partir das células desta zona meristemática. 


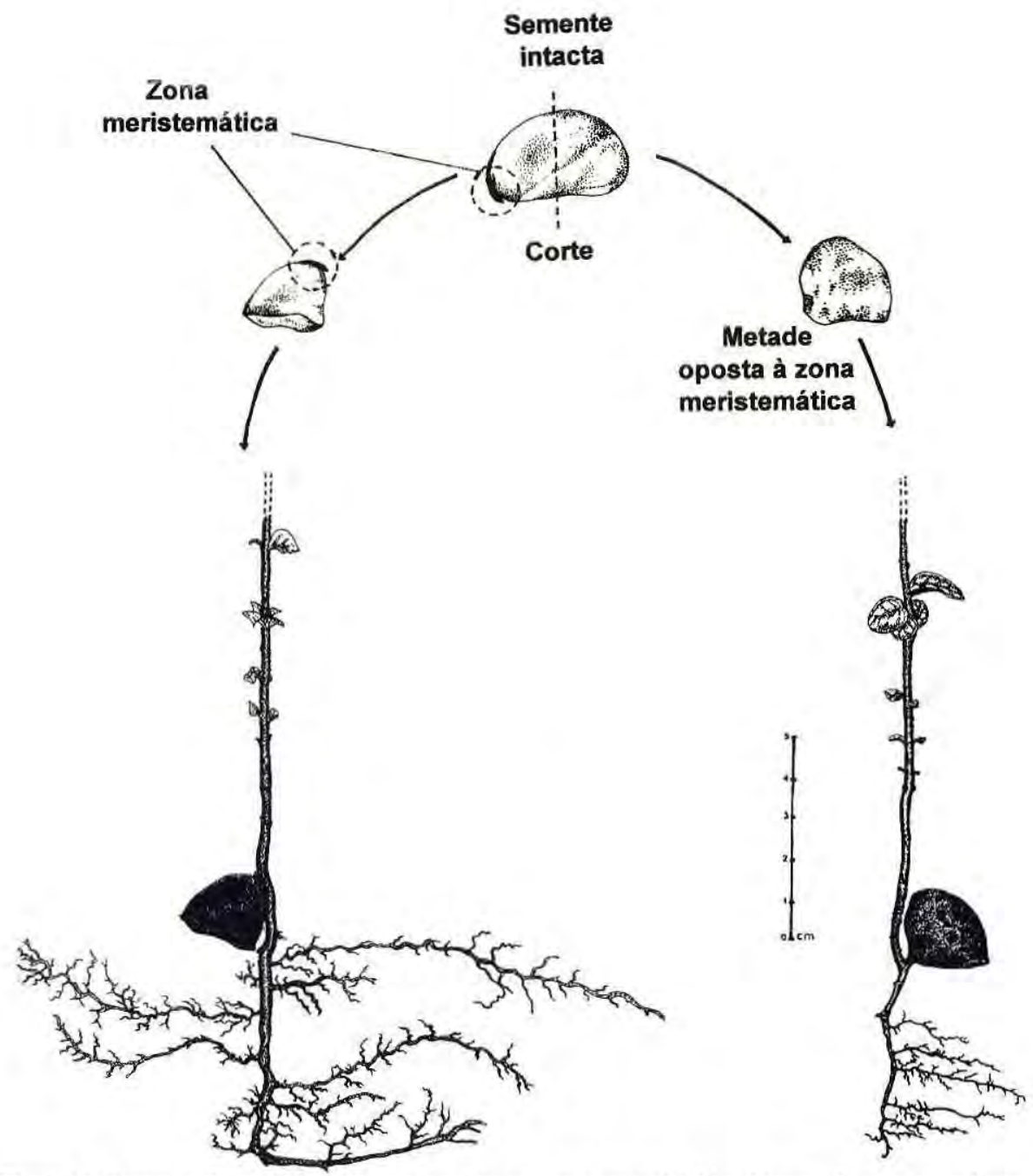

Figura 5. Semente de araçá-boi (Eugenia stipitata ssp. sororia McVaugh) cortada transversalmente ao meio e semeada. Na metade da esquerda ocorreu a germinação normal na zona meristemática. Na metade da direita houve a regeneração de uma plântula na borda da área do corte.

Devido à complexidade morfológica da semente, são necessários estudos sobre sua ontogenia e anatomia de sua germinação.

\section{Regeneração após injúria}

Os testes de corte nas sementes, visando observar os efeitos da injúria na germinação, mostraram que as sementes são muito resistentes a danos fisicos. Das
100 sementes que foram cortadas ao meio e semeadas com as superficies dos cortes voltadas para baixo (Fig. 5), houve germinação em $89 \%$ das metades que contém a zona meristemática. Surpreendentemente, houve também formação (regeneração) de plântulas em $20 \%$ das metades opostas à zona meristemática (Fig. 5). As 100 sementes cortadas na zona meristemática também não foram 
afetadas pela injúria, pois em $77 \%$ houve desenvolvimento de plântulas normais (Fig. 6).

É interessante observar que, nas sementes cortadas ao meio, as metades com a zona meristemática não formaram plântulas na superfície do corte. Já nas metades opostas à zona meristemática, houve formação de plântulas na superfície do corte. Isto mostra a polaridade da semente que provavelmente se baseia na migração dos hormônios auxina e citocinina, tal como observado em caules por alguns autores (Fosket, 1994; Mohr \& Schopfer, 1995). A semente de araçáboi mostrou-se altamente regenerativa, mantendo uma polaridade semelhante

\section{Semente}
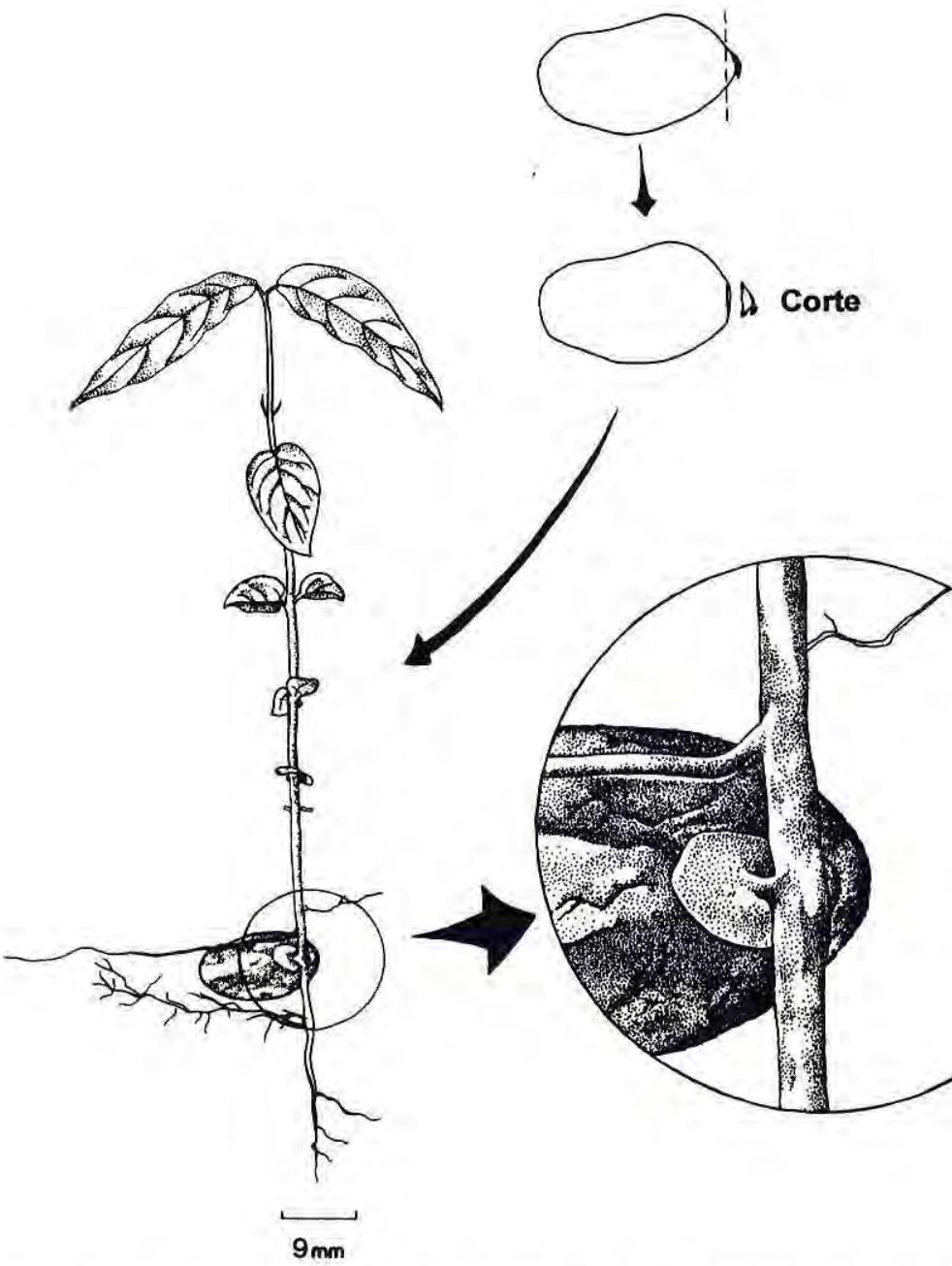

Figura 6. Semente de araçá-boi (Eugenia stipitata ssp. sororia McVaugh) cortada na extremidade meristemática e semeada, evidenciando a germinação (regeneração) na área do corte. 
à de um caule quando segmentado para formação de estacas. Isto significa que a semente, quando cortada, comporta-se como um caule e parece possuir um gradiente hormonal que converge da região distal para a zona meristemática.

\section{AGRADECIMENTOS}

Os autores agradecem a Daniel O. Gentil e Prof $f^{\mathfrak{a}}$ Marta Falcão pelo fornecimento das sementes, ao Dr. John H. Harwood pela confecção do abstract e a Angelic K. Nara pela realização dos desenhos.

\section{Bibliografia citada}

Chavez Flores, W.B,; Clement, C.R. 1984. Considerações sobre o araçá-boi (Eugenia stipitata McVaugh, Myrtaceae) na Amazônia brasileira. Anais do $7^{2}$ Congresso Brasileiro de Fruticultura. Soc. Bras. Frutic., Florianópolis, Brasil. p. 167-177.

Clement, C.R. 1983. Underexploited Amazonian Fruits. Proc. Am. Soc. Hortic. Sci.Trop. Reg., 27(A): 117-141.

Ferreira, S.A.N, 1989. Efeito do tamanho da semente e do substrato sobre a emergência e vigor de plântulas de araçá-boi (Eugenia stipitata McVaugh), Anais do $10^{\circ}$ Congresso Brasileiro de Fruticultura. Soc. Bras. Frutic., Fortaleza, Brasil. p. 33-40.

Flores, E.M.; Rivera, D.I. 1989. Criptocotilia en algunas dicotiledoneas tropicales. Brenesia, 32: 19-26.

Font Quer, P. 1985. Diccionario de Botánica. Editorial Labor S/A, Barcelona. 1244p.
Fosket, D.E. 1994. Plant growth and development: a molecular approach. Academic Press, New York. 580p.

Gentil, D.F.O.; Ferreira, S.A.N. 1999. Viabilidade e superação da dormência $\mathrm{em}$ sementes de araçá-boi (Eugenia stipitata ssp, sororia). Acta Amazonica 29(1): 21-31.

Hladik, A.; Miquel, S. 1990. Seedling types and plant establishment in an african rain forest. In: Bawa, K.S.; Hadley, M. (Eds.). Reproductive ecology of tropical forest plants. Man and Biosphere 7 UNESCO \& The Parthenon Group, Paris. p. 261-282.

King, M.W.; Roberts, E.H. 1979. The storage of recalcitrant seeds. Achievements and possible approaches. International Board for Plant Genetic Resources, Rome. 96p.

Lughadha, E.N.; Proença, C. 1996. A survey of the reproductive biology of the Myrtoideae (Myrtaceae). Ann. Missouri Bot. Gard., 83: 480-503.

McVaugh, R. 1956. Tropical American Myrtaceae. Fieldiana Botany, 29(3): 145-228.

McVaugh, R. 1958. Flora of Peru. Field. Mus. Nat. Hist. Bot., 13: 736-737.

Mohr, H.; Schopfer, P. 1995. Plant physiology. Springer Verlag, Berlin. 629p.

Pinedo Panduro, M.H.; Ramirez, N.F.; Blasco, L.M. 1981. Notas preliminares sobre el araza (Eugenia stipitata McVaugh), frutal nativo de la Amazonia Peruana. (Publ. Misc., 229). Ministerio de Agricultura y Alimentación, Instituto Nacional de Investigación Agraria \& Instituto Interamericano de Ciencias Agricolas, Lima, Peru. 58p.

Toledo, F.F.; Marcos Filho, J. 1977. Manual das sementes: tecnologia da produção. Ed. Agronômica Ceres, São Paulo. 224p. 